\title{
CES
}

COOPERATIVISMO E ECONOMÍA SOCIAL

Núm. 40 (2017-2018), páxs. 243-253

ISSN: $1130-2682$

\section{BALDIOS, REGIME FLORESTAL PARCIAL E CASA DE GUARDA: DE QUEM É, AFINAL, A CASA? ANOTAÇÃO AO ACÓRDÃO DO TRIBUNAL DA RELAÇÃO DE GUIMARÃES DE 9 DE NOVEMBRO DE 2011, PROFERIDO NO ÂMBITO DO PROCESSO 512/13.6TBMNC.G1}

EMPTY LOTS, PARTIAL FOREST REGIME AND GUARD HOUSE: WHO DOES HOUSE BELONG TO AFTER ALL? COMMENTARY TO THE JUDGMENT OF THE GUIMARÃES COURT OF APPEAL OF NOVEMBER $9^{\text {TH }}$, 2011, PURSUANT TO THE PROCEDURE 512 / 13.6TBMNC.G1

\author{
Fernanda Paula Oliveira e Dulce Lopes*
}

Professoras da Faculdade de Direito da Universidade de Coimbra. Faculdade de Direito, Pátio da Universidade, Coimbra. Enderezo de correo electrónico: fpaula@fd.uc.pt; dulce.rdgr@gmail.com. 



\section{ANOTAÇÃo}

- É hoje consensual que os baldios são bens comunitários, não fazendo parte $\boldsymbol{i}$. nem do setor público, nem do setor privado, antes integrando o setor cooperativo e social. Neste se integram, efetivamente, de acordo com a alínea b) do n. ${ }^{\circ} 4$ do artigo $82 .^{\circ}$ da Constituição da República Portuguesa, além de outros, "os meios de produção comunitários, possuídos e geridos por comunidades locais". No mesmo sentido vai a Lei que aprovou o regime aplicável aos baldios e demais meios de produção comunitários (Lei n. ${ }^{\circ}$ 75/2017, de 17 de agosto), que integra no setor cooperativo e social dos meios de produção a que se refere a alínea b) do n. ${ }^{\circ} 4$ do artigo $82 .^{\circ}$ da Constituição, os baldios que sejam possuídos e geridos por comunidades locais (artigo $1 .^{\circ}$ ).

Isto significa que são as comunidades locais, enquanto comunidade de habitantes que se apresentam como titulares dos seus direitos coletivos (sejam de gozo, de uso, ou de domínio), valendo, quanto a elas, os princípios da autoadministração e autogestão ${ }^{1}$.

Resulta do artigo $2 .^{\circ}$, alínea c), desta lei que comunidade local corresponde "ao conjunto de compartes organizado nos termos da presente lei que possui e gere os baldios e outros meios de produção comunitários", sendo este universo de compartes integrado por "cidadãos com residência na área onde se situam os correspondentes imóveis, no respeito pelos usos e costumes reconhecidos pelas comunidades locais, podendo também ser atribuída pela assembleia de compartes essa qualidade a cidadão não residente" (n. 2 do artigo 7. ${ }^{\circ}$ ).

Acresce que a Lei n. ${ }^{\circ}$ 75/2017 atualmente em vigor, define baldios como os terrenos com as suas partes e equipamentos integrantes, possuídos e geridos por comunidades locais [artigo $2 .^{\circ}$, alínea a)], considerando os compartes os titulares dos baldios (artigo $7 .^{\circ}, \mathrm{n} .^{\circ} 1$ ).

ii. Uma das questões que, a propósito dos baldios, tem sido discutida na jurisprudência prende-se com as consequências da situação de sujeição de terrenos baldios ao regime florestal parcial, nos quais foram erigidas, pelo Estado, casas de guarda, para finalidades de vigilância dos terrenos florestais.

\footnotetext{
1 Impressivamente, veja-se o Acórdão do Tribunal Constitucional n. ${ }^{\circ}$ 96/2012, segundo o qual "Na verdade, os baldios não são matéria que, à partida, deva ser considerada de poder local. Havendo assembleia de compartes é a esta, como conjunto de compartes de um bem comunitário gerido e possuído pela comunidade, e não aos eleitores recenseados que cabe decidir as questões que aos baldios respeitam".
} 
Esta submissão ao regime florestal parcial de terrenos baldios, iniciada já em 1901 (Decreto de 24 de dezembro) foi historicamente objeto de grande contestação e apontada como um dos principais motivos para o declínio daquela forma de propriedade comunitária, pela sua arborização compulsória e a sua gestão centralizada.

Mais recentemente, os conflitos entre o Estado (em particular a sua administração florestal) e os órgãos de gestão dos baldios têm-se centrado quer na questão da própria devolução dos Baldios [que, ainda que mandatada pelo Decreto-Lei n. ${ }^{\circ}$ 39/76, de 19 de janeiro e revigorada pelo artigo 2 . $^{\circ}$, alínea a) ii) da Lei n. ${ }^{\circ} 75 / 2017$, tem encontrado oposição do Estado, por este considerar que tal poderia frustrar os objetivos do regime florestal em que aquelas áreas se encontram inseridas] quer na questão do âmbito dessa devolução.

É esta última a questão que nos ocupa na anotação ao Acórdão do Tribunal da Relação de Guimarães, de 9 de novembro de 2017: a de aferir se, tendo havido lugar à devolução aos compartes do uso, fruição e administração dos baldios, tal devolução abrange as casas de guarda e as parcelas de terrenos dos baldios em que foram implantadas casas dos guardas florestais, assim como os anexos de apoios a tais casas e respetivos logradouros, ou se tais casas de guarda e parcelas assim ocupadas permanecem afetas ao Estado.

Note-se que o terreno baldio em causa nos autos em apreço foi submetido ao regime florestal parcial através do Decreto do Governo, publicado no Diário do Governo n. ${ }^{\circ} 240$ da II. ${ }^{a}$ Série, de 14 de outubro de 1944, que o reconheceu como próprio para a execução da Lei n. ${ }^{\circ}$ 1971, de 15 de junho de 1938.

Importa realçar que o regime florestal parcial, ao contrário do regime florestal total, incidia apenas sobre terrenos que não eram propriedade do Estado e que não adquiriam esse estatuto por via daquela afetação. Da Base VI da Lei n. ${ }^{\circ} 1971$, de 16 de Junho 1938, resultava apenas que "os terrenos baldios, depois de submetidos ao regime florestal, entram na posse dos serviços à medida que forem arborizados ou a contar da respectiva notificação" (sublinhado nosso).

De onde não se poder afirmar, desde logo, que os bens em apreço integraram o domínio privado ou público do Estado, ingressando na sua propriedade. O Estado passou, isso sim, a deter, por força destes diplomas, um conjunto de poderes e direitos funcionalizados sobre os terrenos baldios (que assim permaneceram), que incluíam, no essencial, a gestão/ exploração florestal desses espaços e a sua vigilância. Este acervo de poderes do Estado projetava-se na esfera jurídica dos compartes, seja inviabilizando a utilização direta dos baldios por eles, seja obrigando-os a suportar um conjunto de ações tomadas pelo Estado com o intuito de cumprir as finalidades de interesse público subjacentes ao regime florestal parcial.

E era nestas finalidades, em particular na de vigilância, que se incluía a construção de casas de guarda e de postos de vigia: a construção destas casas tinha em 
vista fornecer aos respetivos guardas habitações dentro da área florestada ou nos limites desta, porquanto a estes competia a sua vigia de dia e de noite, como consta do artigo $305 .^{\circ}$ do regulamento para a Execução do Regime Florestal, aprovado por decreto de 24 de dezembro de 1903.

Ou seja, no ónus que passou a incidir sobre os baldios em virtude da sua integração no regime florestal parcial (portanto, um ónus real) integrava-se a possibilidade de, em ligação com as respetivas áreas florestadas, se prever um espaço edificado que cumpria funções indissociavelmente relacionadas com aquela gestão florestal.

Precisamente, a Base VIII da Lei n. 1971 alude às casas de guarda, ao estipular que dos projetos definitivos, além da "área a arborizar e a reservar para pastagens, viveiros culturas" [alínea a)], conste, entre outros aspetos, a "construção de caminhos, sedes de administração, casas de guarda, postos de vigia, montagem de rêde telefónica (...)]» [alínea c)], podendo as construções "que tenham de preceder os trabalhos de urbanização (...) constar de projectos especiais”. Em momento algum, porém, se refere nesta Lei, a constituição de um direito de propriedade a favor do Estado ou a integração de terrenos comunitários no domínio estadual, por esta transferência de propriedade não ser necessária para a prossecução das finalidades públicas em apreço: a mera sujeição de terrenos comunitários a um regime legal restritivo de uso do solo (a par do que hoje sucede com inúmeras servidões e restrições de utilidade pública) cumpria as exigências públicas de intervenção, orientação e gestão florestal, não tendo sido necessário expropriar ou transferir por qualquer outro modo a propriedade das parcelas em causa $^{2}$. Se assim não fosse, mal se compreenderia a distinção legal entre regime florestal total e parcial.

Por isso se compreende que várias pronúncias que têm vindo a ser emitidas sobre esta matéria, enfatizem, quanto a nós bem, que em momento algum o legislador atribuiu ou permitiu a atribuição da propriedade ao Estado sobre aquelas parcelas (aquelas sobre as quais se implantaram casas de guarda). É isso que resulta, por exemplo, do Parecer n. ${ }^{\circ}$ 151/78, da Procuradoria Geral da República, de 30 de agosto de 1978 (in Boletim do Ministério da Justiça, 284-72), segundo o qual em causa estaria "um direito real, sujeito a um regime de direito público,

\footnotetext{
2 Tal expropriação apenas ocorreria em situações contadas. Assim, segundo o Decreto que criou o regime florestal (Decreto Orgânico dos Serviços Agrícolas, de 24 de dezembro 1901), se houvesse parecer desfavorável, os proprietários podiam requerer a expropriação "pela qual a mata ou os terrenos a arborizar passam para a posse do Estado em regime florestal total" (artigo $33^{\circ}, \S 2^{\circ}$ ). Mais, previa-se no $\S$ único do artigo $34 .^{\circ}$ deste Decreto que "Os terrenos de particulares que devam ser arborizados sob o regime florestal, assim como as matas particulares que convenha submeter ao mesmo regime podem ser expropriados pelo Estado, se os respectivos proprietários se não sujeitarem às condições do regime florestal parcial, nos termos do regulamento", o qual determinará igualmente "as condições e prazos em que deverão ser feitas a arborização dos terrenos e a exploração das matas dos particulares, dos grémios e associações, bem como das corporações administrativas e estabelecimentos pios".
} 
cabendo ao Estado a posse dos imóveis correspondente a esse direito". Escreve-se aí, igualmente, que "o conteúdo do direito do Estado é mais amplo do que o do arrendatário ou administrador", sem, porém, o ter equiparado em momento algum ao direito de propriedade.

Todavia, a nossa dúvida vai mais além do que aquilo que tem vindo a ser discutido e decidido na jurisprudência (que se tem pronunciado ora no sentido de reconhecer ao Estado a propriedade sobre as parcelas onde se implantam as casas de guarda ora de recusar tal reconhecimento). Vejamos que dúvida é essa.

O discurso que tem vindo a ser feito nesta matéria tem encontrado base jurídica no Parecer nº 6/99 da Procuradoria Geral da República, de 24 de junho de 1999 (Diário da República, II. ${ }^{a}$ Série, de 24 de novembro de 1999), segundo o qual o regime esboçado aponta no "sentido de um direito real do Estado sobre os baldios sujeitos ao regime florestal funcionalmente dotado de grande estabilidade e de vincadas características de exclusividade e oponibilidade a terceiros, cujo conteúdo se aproxima, quando não se identifica, em certos dos seus vectores, com o complexo de poderes e direitos próprios do titular da propriedade".

Como se pode inferir do texto acabado de citar, também este Parecer não se pronuncia, quanto ao solo - isto é, quanto às parcelas integradas nos baldios como sendo propriedade do Estado; apenas que a sua sujeição a regime florestal parcial comporta limites que se aproximam do vetor essencialmente negativo daquele direito (o de excluir terceiros e, mesmo, os proprietários, da sua fruição e utilização).

Porém, atente-se que este Parecer vai mais longe, já que assume a submissão ao regime estrito de direito de propriedade os bens jurídicos (as construções) que se implantam sobre aquele solo. Como aí se afirma: "Determinadas coisas, inclusive, aí existentes, encontram-se inequivocamente no domínio (privado) do Estado; a floresta, plantada pelos serviços florestais; as construções de várias espécies aí edificadas e custeadas pelos serviços estaduais, com relevo para as casas de guarda, cuja propriedade não suscita na consulta sombra de dúvida de que se encontra na titularidade do Estado" (sublinhados nossos).

De acordo com esta tese, as casas de guarda são propriedade do Estado pelo simples facto de terem sido por ele construídas, não se invocando qualquer fundamento jurídico para o efeito, seja a acessão, seja a usucapião, seja a constituição de um direito de superfície. Neste raciocínio, bastaria ao Estado ter construído as casas de guarda e outras edificações em terrenos que não lhe pertenciam para que, como que por artes mágicas, se constituísse na sua esfera jurídica um direito de propriedade sobre elas.

Assinale-se a este propósito que, tal como para o solo (isto é, para as parcelas nas quais se implantam as casas) o legislador não previu para a edificação qual- 
quer regime particular, designadamente não previu qualquer forma de aquisição de um direito real sobre a mesma.

Não se percebe, portanto, a assunção imediata e acrítica de que "as casas de guarda são propriedade do Estado", ainda que não tenhamos quaisquer dúvidas sobre a legitimidade que o Estado tinha para, ao abrigo do regime florestal parcial, as construir em terrenos de terceiros e para as manter enquanto subsistissem as finalidades públicas subjacentes à sua edificação e às quais elas estavam funcionalizadas. Se, de facto, o que justificou a constituição de restrições de utilidade pública ao uso dos baldios pelos seus compartes (com os ónus delas decorrentes) foi a submissão a um regime florestal parcial e, portanto, a aplicação de um regime jurídico de direito público (um direito real público), não se percebe a necessidade e adequação de se formatar o estatuto jurídico das casas de guarda à luz de conceitos puramente privatistas (direito de propriedade privada). E, além do mais, sem explorar cabalmente estes regimes pois vemos com particular dificuldade que se possa considerar que a construção em terreno alheio corresponde, sem mais, à criação de um qualquer direito de propriedade apenas sobre o edifício.

Muito menos se analisou se terá havido alguma afetação destas casas de guarda ao domínio público ou privado indisponível estadual nos moldes jus-publicistas. Isto porque, como é sabido, os bens do Estado tanto podem integrar o domínio público (aqueles que como tal assim sejam considerados pela constituição e pela lei ${ }^{3}$ ) como o domínio privado (os restantes), sendo necessário distinguir, quanto a este, se se trata do domínio privado indisponível (sujeitos a um regime restritivo próximos dos bens do domínio público) ou disponível ${ }^{4}$.

$\mathrm{E}$, anote-se, mesmo aqui, que apenas são sujeitos a um destes regimes os bens que inequivocamente sejam do Estado, isto é, tenham por ele sido adquiridos, quer por via privada (o que, como vimos, não ocorreu), quer por via pública (por

\footnotetext{
3 A categoria dos bens públicos é constituída pelo conjunto de coisas, pertencentes a um determinado ente público (normalmente a título dominial), submetidas por lei a um regime especial (em que avulta a sua tendencial incomerciabilidade) e individualizáveis com base em específicos carateres objetuais ou naturais legalmente fixados (bens reservados) ou por força da sua concreta destinação a uma função ou serviço públicos (bens de destinação pública). A qualificação como pública conferida a uma coisa subtrai-a, por regra, ao comércio jurídico privado e submete-a ao domínio de uma pessoa coletiva de direito público para ser disponibilizada para uso público ou aplicada à satisfação de certos interesses públicos.

4 Os bens do domínio privado disponível estão sujeitos a um regime distinto: trata-se de bens que, por regra, não se encontram adstritos a nenhuma finalidade pública específica (o que decorre, muitas vezes, do facto de terem sido adquiridos pela Administração de forma ocasional, nomeadamente por intermédio de doações particulares ou de execuções fiscais), tendo uma mera finalidade de produzirem rendimentos. Porém, a sua disponibilidade não significa uma sujeição total ao direito privado: ainda que possam ser alienados ou onerados pela Administração e objeto de tráfico jurídico normal, tal apenas pode ser concretizado nas formas prescritas na lei administrativa, designadamente por via concursal.
} 
ato de autoridade, designadamente expropriação, ou por via legal). O que também não sucedeu.

Nunca é demais relembrar que a lei não determina a transmissão da propriedade sobre os baldios (ou de qualquer bem neles construído) para o Estado, apenas da sua posse. Nem foram constituídos quaisquer direitos a favor do Estado que lhe permitissem edificar em terreno alheio, não tendo sido mobilizado os institutos da expropriação da parcela a afetar a esse fim ou da constituições de direitos reais públicos menores como os de servidão ou de superfície que viabilizassem a constituição de um direito de propriedade sobre as casas de guarda a favor do Estado.

Portanto, existe um salto (i)lógico, que não se entende nem tem fundamento jurídico, na afirmação de que as casas de guarda são propriedade privada do Estado.

Mais apreensões nos suscita a conclusão do referido Parecer segundo a qual "As parcelas de terreno dos mesmos baldios em que foram implantadas as casas de guarda tornaram-se indissociavelmente partícipes da destinação pública a que estas foram afectadas, mercê da qual, e por força do direito real público aludido na conclusão 1., ficaram exceptuadas da devolução ao uso, fruição e administração dos baldios aos compartes, nos termos do artigo $3^{\circ}$ do Decreto-Lei n. ${ }^{\circ} 39 / 76$, de 19 de Janeiro".

Ou seja, seguindo esta linha de raciocínio, as casas de guarda, sendo propriedade privada do Estado, trazem consigo a acessória propriedade estadual das parcelas em que se implantam. A finalidade pública a que se encontram adstritas as casas de guarda projeta-se sobre o terreno na qual as mesmas se implantam convertendo-o (de novo sem que se indiquem figuras jurídicas que o justifiquem) em propriedade privada do Estado.

Este argumentarium esquece que o que é essencial no regime legal gizado já em 1901 não são as casas de guarda, mas sim a exploração florestal pelo Estado de terrenos não estaduais. Este sim o fundamento do regime florestal parcial e da consideração de que os terrenos arborizados passariam para a posse do Estado, mantendo, contudo, a sua titularidade originária. As casas de guarda são elas, assim, um elemento acessório à gestão e vigilância florestal e não um uso que deste se autonomize. Usar a "destinação pública" a que foram afetadas as casas de guarda para delas retirar a propriedade estadual dos terrenos sobre a qual se implantam, mesmo nas circunstâncias em que a gestão destes foi devolvida aos baldios, é absolutamente espúrio. Isto porque aquelas casas não se autonomizam da exploração florestal a que se encontraram ligadas, não podendo ser usadas como um elemento independente de ligação ao solo. Elas existem em função das finalidades de exploração florestal, sendo esta a única "destinação pública" relevante.

Fazendo um ponto de ordem nas considerações até aqui expendidas, podemos assentar no seguinte: 
1. As casas de guarda não são qua tale propriedade do Estado; para o serem teria de ter havido um qualquer título jurídico privado ou público de constituição desse direito. O que não excluímos que ocorra em algumas situações, mas não é o cenário que tem sido colocado aos nossos Tribunais;

2. A afetação a um fim de utilidade pública não é, por si só, um título de aquisição da propriedade. E nem o poderia ser pois não se compreende como é que, estando as casas de guarda sujeitas ao mesmo regime público do solo - o regime florestal parcial - aquelas seriam detidas a título de propriedade pelo Estado, que quanto a este seria mero possuidor.

3. As casas de guarda não têm uma "destinação pública" autónoma, estando dependentes da função de exploração e vigilância florestal, pelo que não têm a potencialidade de estender um eventual regime público à parcela sobre a qual se implantam.

Não é isso que a nossa jurisprudência tem entendido, oscilando, porém, entre os que consideram que as parcelas onde se implantam as casas de guarda são consequentemente de propriedade estadual (sujeitas inclusive, como sucede no Acórdão em anotação, ao domínio público deste $)^{5}$, e aqueles que entendem que como não se configura qualquer forma de aquisição originária ou derivada que possa fundamentar a declaração de que a parcela de terreno onde se encontra implantada a casa florestal é propriedade do Estado, ela continua a pertencer ao Baldio. ${ }^{6}$

Não obstante esta discordância quanto à titularidade das parcelas sobre que se implantam as casas de guarda, toda esta jurisprudência está de acordo (ou não questionou) que as casas de guarda, em si mesmas, são propriedade privada do Estado. Ora, é a este propósito que não concordamos com o que tem vindo a ser decidido nos nossos tribunais (de que é exemplo o Acórdão aqui em anotação). A nosso ver não há motivos para distinguir entre o estatuto jurídico real das casas de guarda e o terreno no qual se implantam, não se vislumbrando qualquer fundamento legal do qual resulte a aquisição de propriedade pelo Estado sobre o terreno e sobre as casas de guarda nele implantadas.

Nem se percebe que se faça uma dissociação, não prevista na lei, entre estes dois elementos, uma vez que pode de nada servir ao baldio o reconhecimento de propriedade sobre a parcela na qual se implanta a edificação e o seu logradouro, sabendo que a casa de guarda continua a ser propriedade do Estado, o que impede uma fruição global daquele espaço.

\footnotetext{
5 Cfr., ainda, o Acórdão do Tribunal da Relação do Porto de 22 de fevereiro de 2005, proferida no Proc. 0426749.

6 Cfr. o Acórdão do Tribunal da Relação do Porto de 23 de março de 2006, proferido no Proc. 0630356 e o Acórdão do Tribunal da Relação de Guimarães de 14 de janeiro de 2008, proferido no Proc. 2071/07-1.
} 
iii. Assumindo acriticamente a posição da nossa jurisprudência - de que as casas de guarda são propriedade do Estado - não foi discutida, como referimos supra, o regime de propriedade do Estado que incide sobre essas casas. Considerando que as mesmas foram construídas para serem afetas a uma finalidade pública (aquela que justificou a sua construção), esse regime seria, ele mesmo, público ou, no limite, um regime de propriedade privada indisponível.

Porém, como resulta destes regimes, se cessar essa afetação, tais casas, por deixarem de ter uma destinação pública, permaneceriam na propriedade privada (agora disponível) do Estado, com a consequência de que este a poderia gerir em moldes privatistas, alienando ou onerando aqueles bens (ainda que nas formas previstas na lei). Esta possibilidade, como julgamos resultar óbvio, poderia impactar a fruição dos baldios pela afetação de áreas que lhes são intersticiais a fins que nada têm a ver com eles ou com a inicialmente perspetivada gestão florestal.

Consideramos que o busílis desta questão não é, portanto, a propriedade privada ou pública da casa de guarda e do terreno subjacente (a qual, como referimos na primeira parte deste comentário, temos forte dúvidas que exista), mas a finalidade pública a que a mesma se encontra (ou não) adstrita. Aliás, este é um dos elementos que na jurisprudência citada tem sido relevante no momento de decidir sobre o estatuto jurídico do solo, o que demonstra a essencialidade deste critério na definição do regime aplicável às casas de guarda.

Senão veja-se o Acórdão do Supremo Tribunal de Justiça, de 15 de setembro de 2011, proc. 243/08.9TBPTL.G1.S1: este, não obstante considerar que não houve aquisição por usucapião pelo Estado, entende que "encontrando-se o baldio da Facha submetido ao regime florestal, não ficaram a aludida casa do guarda-florestal, a parcela em que se encontra implantada e respectivo logradouro abrangidos na devolução, ao uso, fruição e administração dos compartes do baldio da Facha”. Mas, para chegar a esta conclusão aduz argumentos adicionais que se prendem, por um lado, com a vontade do Estado em continuar a assegurar a gestão de áreas florestadas ("não tendo o Estado querido abandonar as áreas florestadas, não integradas nos baldios, pretendeu também manter as casas dos guardas florestais, dado que as áreas florestadas, sob vigilância desses guardas, não se confundiam com as áreas dos baldios."); e, por outro lado, com a inutilidade da área em apreço para a gestão do baldio pelos compartes ("Como se considerou no acórdão recorrido, a prossecução das finalidades intencionadas com a devolução dos baldios não exigia a entrega de tais casas ou instalações. Com efeito, a tão vastas áreas de terrenos baldios não adiantam, nem atrasam superfícies da ordem dos $300 \mathrm{~m}^{2}{ }^{2}$. Mais, não se vislumbra que uso iriam os compartes dar a essas instalações, designadamente aos postos de vigia”).

Tendo em conta o afirmado, a nossa posição é muito clara. 
Não há dúvidas que, salvo existindo título bastante nesse sentido, as casas de guarda não são qua tale propriedade pública ou privada do Estado (constituindo quando muito uma benfeitoria e estando sujeita ao regime destas). Porém, também não restam dúvidas que tais casas foram construídas para a prossecução de uma finalidade pública associada à gestão florestal, finalidade esta que, com a devolução dos baldios à gestão dos compartes, pode não ter necessariamente cessado.

\section{COMPREENDAMO-NOS}

Da posição segundo a qual não resulta da mera construção das casas de guarda a propriedade estadual destas deve retirar-se que, como regra, a devolução dos baldios à gestão dos seus compartes abrange também as casas de guarda e, naturalmente, as parcelas nas quais se encontram integradas e respetivos logradouros.

Só assim não acontecerá nas situações - eventualmente residuais - em que o Estado argua e comprove que continua a fazer uso de tais casas de guarda ou de outros equipamentos (como as torres de vigia) para finalidades de exploração e vigilância florestal. Isto porque compreendemos que as finalidades subjacentes ao regime florestal parcial podem não ter sido extintas com a mera devolução de gestão de um baldio, já que, na envolvente, pode haver boas razões para continuar a gerir, manter e vigiar áreas florestadas da responsabilidade do Estado.

Claramente não cumprirão estas exigências situações em que tais casas se encontrem em ruína ou em elevado estado de deterioração, não se encontrem afetas à atividade pública que fundamentou a sua construção ou a uma atividade análoga, ou estejam sujeitas a finalidades privadas.

Dada esta plurifacetada consideração jurídica do problema, se compreende que a Lei dos Baldios não lhe tenha dado resposta, uma vez que uma adequada solução de cada caso carece de uma ponderação concreta das suas circunstâncias. Todavia, julgamos que seria adequado que o discurso jurídico se passasse a centrar decisivamente na finalidade pública que esteve subjacente à construção das casas de guarda (e na sua manutenção ou não) e não na sua titularidade que parece ser deduzida, pura e simplesmente, a partir daquela construção. 